\title{
Looking beyond interaction: exploring meaning making through the windows of an art gallery
}

\author{
Laura Harris $^{1}$
}

Accepted: 30 August 2021 / Published online: 27 November 2021

(c) The Author(s), under exclusive licence to Springer Nature Limited 2021

\begin{abstract}
How is meaning produced in and around the art gallery? Sociological answers to this question are limited by a narrow focus on inter-gallery group interaction and cognitive interpretation. I argue that such approaches would be strengthened by accounting for the diverting effects of gallery context and atmosphere, both in and beyond the gallery. Art gallery windows offer a lens through which to explore how issues of context and atmosphere are negotiated in and around an art gallery in everyday life. I trial this approach using data from a fourteen-month case study of Bluecoat, a city center art gallery in Liverpool, UK, which has a series of windows that mediate between the gallery and the neighboring shopping street. The windows partition zones of meaning; frame vision; contribute to the symbolic meanings of a gallery's exterior architecture; and modulate its interior atmosphere. The analysis models a meaning-centered sociology of the art gallery that moves beyond interpretation and towards a broader understanding of the currents of meaning in and around the art gallery.
\end{abstract}

Keywords Art gallery $\cdot$ Context $\cdot$ Atmospheres $\cdot$ Interaction $\cdot$ Meaning $\cdot$ Windows

\section{Introduction}

Art galleries are alive with the contestation of meaning. Rooted in long traditions of the display and reception of art, galleries are sites in which artworks are carefully arranged, and art-relevant meanings are attached to sensory experience. Due to this density of meaning within them, art galleries have attracted many sociologists, particularly those interested in meaning and its status in social life and analysis. However, as well as territories for the contestation of artworks and their meanings, art galleries are also built environments. Their architectural form and relationship with their surroundings situate

Laura Harris

lharris7@ed.ac.uk

1 School of Social and Political Science, University of Edinburgh, 15a George Square,

Edinburgh EH8 9LD, UK 
them within a matrix of meanings in time and place. Often located in lively social contexts, like city streets, art galleries can be pulled into the orbit of meanings that circulate beyond their walls and windows. In other words, art galleries are not only made meaningful by the artworks within them, but also by the textures of the social life that surrounds them.

In this paper, I am concerned with how sociologists have approached the study of gallery-situated meaning. My central argument is that many of these approaches are limited by their foregrounding of inter-gallery group interaction and the cognitive interpretation of artworks over other situational and contextual factors at play in the art gallery as it is encountered in everyday life. As such, I am intervening in the broad disciplinary discussion of the relationship between meaning and social life (Alexander 2003), in the narrower but longstanding debate around the status of meaning in the sociological study of art (Eyerman \& Ring 1998; de la Fuente 2020a), and in the specific literature that has taken the art gallery as its subject.

I begin with a literature review that identifies "interaction" as a key theme in many meaning-centered sociologies of the art gallery. Turning to broader literature in contemporary cultural sociology, I then suggest that attention to the context and atmosphere of the art gallery would benefit sociological analyses of how meaning circulates in and, crucially, around an art gallery. Highlighting the importance of architecture and gallery aesthetics, I identify art gallery windows as a way to study the unsettled processes by which contexts and atmospheres are negotiated in and around an art gallery, and the consequences this has for the production of meaning. I then offer an overview of the histories that inform the architectural, social, and aesthetic conventions of art gallery windows.

The data for this paper are drawn from a fourteen-month case study of Bluecoat, a city center art gallery in Liverpool, UK. Ethnographic and visual methods were used to follow the course of the planning, construction, and consumption of an exhibition of contemporary art, In the Peaceful Dome. This exhibition was hosted in a wing of galleries, one of which features a series of three floor-to-ceiling windows. These windows give out onto College Lane, a mid- to high-end shopping street that forms part of the shopping complex Liverpool One. As such, the artworks on display in the gallery were clearly visible from the street; likewise, the animation of the street was clearly visible from the gallery. After introducing the field site, data, and methods of my study, I offer an analysis of these windows by way of "thick description" (Geertz 1973, p. 3). This includes detailing how Bluecoat's gallery is entangled with the narratives of College Lane and Liverpool's urban fabric, and how the meanings of the gallery and the shopping street are held apart or held together. As such, the analysis decentralizes the interpretation of artworks in order to bring the experiential and contextual features of the gallery into focus. 


\section{Literature review}

\section{Interaction and its limits}

How is meaning produced in and around the art gallery? Sociologists interested in this question have studied gallery-situated meaning making from a variety of angles (Kirchberg and Tröndle 2012). Some analytical approaches hinge on what visitors to art galleries bring with them, such as their motivations for visiting (Falk and Dierking 2011 [1992]; Kirchberg and Tröndle 2015; Cotter et al. 2021), or their class profile and educational background (Bourdieu and Darbel 1991). Others focus on the action contained within the art gallery, such as how visitors engage with one another (Lehn et al. 2001; Bruder and Ucok 2011; Christidou 2018; Adipa 2019), with interpretative displays (Scott et al. 2013; Steier et al. 2015), or how bodies interact with objects in the gallery space (Griswold et al. 2013; Christidou and Pierroux 2019). From those meaning-centered sociological studies that take the gallery site itself as the unit of observation, a key theme has come to dominate: interaction (Lehn et al. 2001; Heath and vom Lehn, 2004; Bruder and Ucok 2011; Scott et al. 2013; Steier et al. 2015; Christidou 2018; Adipa 2019).

These interactional approaches to studying gallery-situated meaning making are often rooted in observations such as "people naturally engage in conversation when they visit art exhibitions in groups" (Adipa 2019, p. 1) or "most visitors... consider museum visiting as an opportunity for socializing" (Christidou 2018, p. 1). Intergallery social interactions are, therefore, often considered an entry point to understanding meaning making in the gallery. Through their actions, people share the "clues" they hold to the interpretation of artworks (Pierroux 2010; Adipa 2019, p. 7) and draw joint attention to aspects of an artwork that are then made relevant in interpretations (Lehn et al. 2001). As such, group interactions, conversation, and gestures have provided data points for the sociological study of the production of gallerysituated meaning making, which is seen as a shared and discursive practice.

The analytical association between interaction and gallery-situated meaning making can be linked to the rise of "relational aesthetics" in artistic and curatorial practices in the 1990s. "Relational aesthetics" saw the conventional one-directional nature of communication or meaning in gallery-situated art challenged by artists and curators who began to reimagine their audiences as active and essential participants in producing artworks' meanings (Bourriaud 1998; Bishop 2012; Acord 2016). More recently, "socially engaged art practice" has seen artists continuing this trend for connecting artistic meaning with social interactions, often involving working in community settings with activist agendas (Thompson 2012). Within participatory artistic practices, conversation and dialog often sit at the core of the work (Kester 2013). This participatory and discursive impulse in contemporary art practice has been translated into exhibition design. Digital and interactive interpretative materials have been incorporated into the exhibition space with a view to replace the passive, introspective mode of gallery-situated meaning making with one of active 
engagement (Scott et al. 2013). ${ }^{1}$ This tendency is reflected in sociological studies of the gallery that understand gallery visitors as "active meaning makers" (Christidou 2018 , p. 2). The dominance of interaction-based sociologies of the art gallery has, therefore, moved in step with artistic and curatorial practices that have institutionalized the position of the gallerygoer as a social agent in the process of making art meaningful.

As well as being related to art world practices, the association between meaning making, language, and interpretation that operates in these approaches to the gallery has a long sociological tradition (de la Fuente 2019). Many studies of gallerysituated meaning making apply a symbolic interactionist approach, bringing with it the primacy of discourse in empirical studies of culture (Becker and McCall 1990; Denzin 2003 [1992]). It is within this disciplinary heritage that language holds the status of the "primary mediational tool" in studies of the gallery (Steier et al. 2015). As such, many studies locate the emergence, negotiation, and communication of meaning in gallerygoers' conversations, and these are often the main source of data analyzed by sociologists (Bruder and Ucok 2011; Adipa 2019).

This interaction-based understanding of gallery-situated meaning making has afforded useful and detailed analyses of the consumption of artworks. However, it also has its limitations. The first of these pertains to importance placed on discursive practices as the main way in which the gallery is made meaningful. Although this link between discourse and meaning is common among Strong Program approaches, recent calls have been made within cultural sociology to embrace other modalities of knowing. Jeffrey Alexander asks: "Can we ignore the sensuousness of sight [or] the vividness of color? The textures of touch...?" (Alexander 2010, p. 12). These are the kinds of questions that animate the "iconic turn" in cultural sociology. A key stake in this "turn" has been the study of icons and iconicity, wherein "iconic meaning" is seen to emerge from "embodied, sensual impressions, [and] from emotional immersion in the sensual object that confronts us as a thing" (Bartmanski and Alexander 2012, p. 4). This approach refuses to reduce meaning to a discursive property of socio-material life, recognizing instead the asthetic, emotional, and cultural character of meaningful experiences. Relatedly, Eduardo de la Fuente's "textural sociology" has highlighted the "'temporal' and 'spatial,' as well as 'material' and 'symbolic' dimensions, of how the world is shaped and sensed" (de la Fuente 2019, p. 553). Both the "iconic turn" and "textural sociology" underscore the qualities of lived, sensory experience that shape the production of meaning, and suggest that language is not the sole domain of meaning. With regard to art, this challenges the notion that aesthetic experience is rendered meaningful through a process of cognition. Instead, alternative ways of knowing, such as those that call on the senses, can be seen as vital to the meanings of art (Sontag 1966; Inglis 2010). Once gallerysituated meaning has been uncoupled from the cognitive interpretation of artworks, a meaning-centered sociology of the art gallery can take on a much broader remit.

\footnotetext{
${ }^{1}$ For example, see National Gallery X, London's National Gallery's studio exploring digital interpretation of artworks (Musuems + Heritage Advisor, 2019).
} 
It can address itself to the sensory, spatial, temporal, and other characteristics of gallery-situated experiences that animate the gallery with meaning.

A further limitation of these interaction-based studies that I wish to highlight concerns the gallery itself. The art gallery is a unique cultural form, deeply historied with modes and practices of meaning making (Classen 2007). Influential theories of art have long understood the gallery as a crucial institutional mechanism to "confer the status of candidate for [artistic] appreciation" (Dickie 1974, p. 26; Danto 1998). These critiques and histories of the gallery space recede into the background when analysis alights on conversation or interaction alone. This reproduces the conventional "neutrality" of the gallery, which is in fact carefully crafted to condition the modes of meaning making applied within it (O’Doherty 2000 [1976]; Klonk 2009). This erasure of the gallery itself also has the effect of flattening out distinctions between different kinds of art galleries (e.g., commercial or publicly funded) and, thus, the different criteria of meaning making that they bring with them. Finally, and importantly, the art gallery as a social site is riddled with a matrix of potential meanings, including those of the art market (Velthuis 2005), of gallerygoers' intimate emotional lives (Lopez-Sintas et al. 2012), and of the meanings attached to neighboring social spaces that intermingle with the art gallery. Within the art gallery, these registers of meaning overlap, compete, and co-exist. As I will go on to argue, contextual or situational features are therefore non-incidental in an expanded understanding of gallery-situated meaning making.

Within sociological approaches to the study of art and cultural production there are in recent years two themes that fill the gaps I have identified in interaction-based analyses of art galleries: "contexts" and "atmospheres." Both of these themes are key to de la Fuente's "textural sociology" and its invitation for cultural analyses to move beyond text (de la Fuente 2019, 2020a, b). In the following section, I will introduce the literature on these themes and how they apply to the city center art gallery that provides the case study for this paper.

\section{Contexts}

The sociology of art offers a wealth of research into the impact of local context on the production and consumption of art, with contexts like the home (Halle 1993), exercise class (DeNora 2000), or the city of Berlin (Bartmanski and Woodward 2019), studied for how they impact the meanings that artworks afford. Such "terroirdriven practices and logics" are increasingly understood to be central to an understanding of cultural production, the study of which has therefore become entangled with the study of place, localities, and contexts (Luckman 2020, p. 177; Fernándes López et al. 2021). For example, the 2019 collection, Regional Cultures, Economies, and Creativity Innovating Through Place in Australia and Beyond, foregrounds how the "qualities of [a] place" inform non-metropolitan creative economies (Van Leyn and de la Fuente 2019). Crucially, these "qualities" include sensory, spatial, or experiential facets of a place, moving in step with the expanded approach to meaning introduced above. 
This focus on place-based context invites a shifting of the goalposts of meaningcentered sociologies of the art gallery. De la Fuente calls for cultural sociology to adopt a "contextual intelligence" in its analyses, recognizing that places are deeply historied and deeply consequential for the shape that meanings within them come to take (2020b). Art galleries are no different, and the location that they occupy does some meaningful heavy lifting. For example, Olav Velthuis' study of the symbolic meanings of prices on the market for contemporary art details how the location of a gallery informs the meanings made within it. Velthuis finds avant-garde commercial galleries in US cities away from tourist hotspots in order to establish a distinction "between the art market and the wider economy" (2005, p. 29); conversely, galleries selling traditional art (e.g., oil painting reproductions, typically in the secondary market) are to be found in "wealthy tourist towns," "fashionable urban areas" and "in between expensive furniture stores" as they are more comfortable with the nature of their wares as commodities (2005, p. 45). This demonstrates the importance of context for understanding the parameters and criteria of meaning making in an art gallery, a dimension that is lost when analyses are bounded by the gallery interior.

Context also has a role in to play in the availability of candidates for aesthetic appreciation. This is made clear by Varvara Kobyshcha in a study of an outdoor sculpture festival, "Archstoyanie" in Russia (Kobyshcha 2018). Here, Kobyshcha details how artworks emerge (or disappear) as objects for aesthetic attention through a contingent process of "becoming" in which the viewer identifies aspects of their sensory experience as a unified artwork. Kobyshcha details how aspects of the festival's grounds became contested sites for the presence or absence of art; a football pitch that had been installed as an artwork was misrecognized by visitors and the flat area provided instead an opportune camping area (Kobyshcha 2018, p. 488). In detailing this, Kobyshcha is evidencing how attention to place and its qualities illuminates how the emergence or disappearance of the meanings of art are contextually contingent. Taken to the art gallery, this invites critical sociological attention to the local spatial, material, and cultural environs of a particular gallery that feed into the production of meaning within and around it.

\section{Atmospheres}

Closely related to the increased attention to contexts in studies of cultural production is an attention to atmospheres. Atmospheres have been of increasing currency across the social sciences, notably in cultural sociology (de la Fuente 2019), anthropology (Ingold 2012), and architecture (Borch 2014), and have also been introduced into symbolic interactionist approaches to music (de la Fuente and Walsh 2020). In this literature, atmosphere refers to the "invisible character that makes an environment unique and confers on that environment a specific place presence and ambience" (Seamon 2020 cited in de la Fuente and Walsh 2020, p. 211). Atmospheres can be understood as the experiential correlate of place-based contexts as introduced above, expanding the discussion of place to include how the social, cultural, economic, and other orderings of a place's meanings are felt and lived. For example, the differing 
atmospheres of night and day have been explored for the ways in which meanings differentially circulate during them (Edensor 2017).

Atmospheres therefore help to differentiate the world into different domains of meaning and significance. For this reason, the concept has been readily taken up by those interested in how places, especially urban ones, are designed such that they produce a certain character of experience in a process that has been called the "setting of ambience" (Thibaud 2015, p. 39; Edensor and Sumartojo 2015). Art galleries, as spaces wherein meaning is highly contested, offer a useful case study of this process. In his contribution to "Iconic Power: Materiality and Meaning in Social Life," Alexander details the architectural style and critical reception of Yale Art Gallery's restoration (Alexander 2012). The function of the art gallery to provide a "sacred" space for art, set apart from "profane," non-art domains of thought and experience, is at the core of this discussion. Alexander details the aesthetic properties of the building, the histories and narratives of Yale as an elite University, the reputation of the architect Louis Khan and architectural critics, and the twists and turns of the architectural canon, from which the building derives its iconic power (Alexander 2012, p. 28-32). This demonstrates the richness of the art gallery as a site through which to study the creation of atmospheres, in this case a sacrosanct atmosphere that is held in a dynamic tension with the "profane" (or simply "nonart") domains of thought and experience that surround it.

Beyond gallery external architecture, aesthetic strategies within art galleries have been institutionalized as the material basis of the atmospheres of modern and contemporary art. For the purposes of this paper I limited myself to the "white cube" gallery aesthetic, which has come to be synonymous with the globalized market for art and its meanings. ${ }^{2}$ This is a type of space characterized by minimal ornamentation, "neutral" background colors (except when a specific artistic or curatorial intervention is taking place), cold ambient lighting, art works distributed relatively sparsely around the space, and an atmosphere of quiet reflection (again, bar specific interventions) (O’Doherty 2000 [1976]). Art historian Charlotte Klonk locates New York's Museum of Modern Art (MoMA) as the propagator of the "white flexible art container," although Klonk notes that the Bauhaus had begun to establish the gallery aesthetic in their exhibitionary experiments (Klonk 2009, p. 137). It is through MoMA's rise to symbolic power that the "neutral" and minimal gallery aesthetic, and the ambience it "sets," came to be institutionalized and standardized as the manifestation of the atmosphere of gallery-situated art. The politics and social relations embedded in the white cube has long been a subject of critique for the exclusionary and elitist notion of art that it upholds (Gumbrecht and van den Berg, 2010). As such, contemporary curatorial practice often plays with or subverts the convention, but the minimal gallery aesthetic nonetheless remains the dominant measure against which such experiments are calibrated.

Likewise, art gallery and museum architecture, and influential architects of the art world, have been widely studied (Crimp \& Lawler 1993; MacLeod 2013;

\footnotetext{
2 The influential and trendsetting "White Cube" chain of commercial galleries, with branches in London and Hong Kong, epitomizes the overlap between this gallery aesthetic and the art market.
} 
Patterson 2019; Lindsay 2020). A history is charted from the "marble palaces" of the late 1800s and early 1900s, like New York's Metropolitan Museum of Art (Steffensen-Bruce 1998), through "postmodern museums" like the Centre Pompidou that began to appear in the 1970s (Crimp \& Lawler 1993, p. 282), to the "iconic" and "place-making" designs, like the Guggenheim Bilbao, popular since the turn of the century (Macgregor 2020; Thompson 2020; Fernándes López et al. 2021). A key stake in contemporary art gallery and museum architecture is the engagement of the "public" with the building's spaces and meanings. This is part of the same participatory impulse in contemporary art and curatorial practice detailed above (2.1). This appetite for public engagement with the art gallery and museum marks a shift in the desired atmospheres of art spaces, from a reified atmosphere signified by the neoclassical museum to an open and accessible space, an "urban living room" (Lykins Reich 2020). The vogue also moves in step with strategies of urban place making that fuse cultural and commercial urban economies (Scott 2000). However, this "open" design principle jars with the white cube gallery aesthetic with its atmosphere of distinction. Contemporary art gallery architecture therefore becomes an exercise in balancing these twin desires: an open atmosphere that nonetheless establishes a special place for art and its meanings.

Bringing the lens of atmosphere to the art gallery exposes the many different domains of meaning that the art gallery as a social, emplaced site is engaged with. This broadens the purview of a meaning-centered sociology of the art gallery. The interpretative strategies of the gallerygoer are only one aspect of the wider circulation of meanings in and around an art gallery. Existing in time, place, and everyday life the art gallery is caught up in orders of meaning relative to its context, the history of artistic display, and the codes and narratives of its architecture. This approach to gallery-situated meaning is at once more expansive and less explicit than those which prioritize discursive strategies. I will now move on to introduce a device that helps to bring the themes of context and atmosphere to bear at an art gallery: its windows.

\section{Art gallery windows}

Windows, especially those of transparent glass, make places porous. They offer a material site through which divergent zones of meaning making come into sensory and visual contact with one another. In this respect, windows represent what Eviatar Zerubavel has called a "fine line"- a partition that divides one meaningful entity from another (Zerubavel 1991) - while also affording the cross-contamination of a space with its neighbor. As an architectural feature of an art gallery, windows therefore play a crucial role in determining how an art gallery interacts with its contexts, creates and upholds its internal atmosphere, and intervenes in the creation of meaning in and around it. By allowing vision to bisect its plane, art gallery windows offer up the objects on display within the gallery to spaces with differing logics and sociocultural orderings, such as a neighboring street. The window is therefore a "hot" site in the maintenance of the gallery as meaningful space for art, allowing both the 
potential for meaning to spill out from the gallery, and for meaning to be projected into it.

I am not the first to suggest that windows repay sociological attention (see Hirsch and Smith, 2017). That glass and windows, specifically shop windows, create and uphold divisions, spatialize social lives, and curate desires is well documented (Bowlby 2001; McQuire 2013; Garrison 2015). Glass has been studied as a significant architectural design element of landmark buildings like Crystal Palace (Jones 2020 , p. 74). Sociologists have shown domestic windows to be highly "symbolically charged" when it comes to issues of local belonging, social inequalities, and social divisions (Hirsch and Smith, 2017, p. 230), and have explored their function as communicative devices for houses isolated by COVID-19 related lockdowns (Mosteanu 2021). Windows also feature in art history. "Viewing stations"- built interventions in nature popularized during the Picturesque movement-provided windows that looked out onto and framed a landscape according to the aesthetic principles of the movement. This demonstrates a function of windows, which is to impose a degree of order and abstraction on the views they offer. Windows also became a trope in Romantic paintings, providing a pictorial device to explore relationships between the private and public, the internal and external, and between the domestic and natural (Smith 2011). As such, in both sociology and art history, windows have offered a lens for studying the situated production and manipulation of meaning.

Art gallery windows have attracted study. Velthuis has shown that windows are a site by which art galleries make manifest their intended character. With reference to US-based commercial galleries, Velthuis describes how a gallery signifies its inclusivity or exclusivity by leaving windows transparent (inclusive) (2005, pp. 32, 46) or frosting them (exclusive) (p. 30). In a discussion of the trend for "open" and accessible contemporary art gallery architecture, William Smart links the "fascination of the modern architecture movement with glass and its transparent materiality" with an "intent to engage with a building's surrounding environment" (2020, p. 138). However, Smart goes on to argue that "the concept of openness goes beyond visual transparency, it embraces how a museum can engage with its community to form a social and cultural hub" (Smart 2020, p. 139). ${ }^{3}$ Transparent glass windows, in other words, are only one agent in the process of the gallery's negotiation with its context; additional practices, such as those of passers-by or gallerygoers, confirm or contest a gallery's "openness." Smart's parallel concepts of "openness" and "transparency" therefore provide a way to think about the contestation of meaning through and around art gallery windows.

Art gallery windows do more than uphold or dissolve the distinction between the zones of art and commerce, or public and private, in urban centers such as the one of interest to this paper. The logics of contemporary city planning are also informed by an appetite for culture-led strategies of place making, and the generation of the

\footnotetext{
3 Smart uses the word "museum" while drawing on examples including Fondazione Prada Milano, White Rabbit Gallery, and Art Gallery of New South Wales, all establishments that would fall (in this paper) into the category "art gallery." This is reflective of the different uses of the words "museum" and "art gallery" in different national contexts.
} 
marketable urban affects of cultured cosmopolitanism (Scott 2000). This is particularly the case in the city of Liverpool, where the data for this paper were generated (Jones and Wilks-Heeg 2004). Within this local economy, the art gallery (and cultural industries more generally) can be understood as instrumental in the branding, tourism-driven imagining of city centers as sites of rich cultural life. As such, art gallery architecture becomes a material manifestation of the overlap of commercial and aesthetic or cultural economies. This can be seen in the prevalence of "starchitects" whose trademark design languages suit both shops and art galleries, creating buildings with similar outward-facing affects; or that collapse the distinction even further, such as Zaha Hadid's Chanel Mobile Art Pavilion, or Frank Gehry's Fondation Louis Vuitton (Paris). Through the work of starchitects like these, glassy and glossy architectural materials (like windows and glass) have become synonymous with affects of glamor and cosmopolitanism in the contemporary city, not least because glass brings with it historical "associations of modernity" (de la Fuente 2019, p. 559; Jones 2020, p. 74). Therefore, the choice of the architectural materials of art galleries, such as glass, bears significance, linking the built form of an art gallery to the logics of contemporary urban spaces.

Finally, art gallery windows also contribute to the atmosphere established in its internal spaces; they are agents in the "setting of ambiance" (Thibaud 2015, p. 39). By determining the quantity and quality of light within the gallery space, windows help craft the atmosphere that curators wish to establish for certain exhibitions. The rise in digital media and immersive installation within art galleries has occasioned an increase in darkened gallery spaces with blacked-out windows. However, the archetypical white cube gallery aesthetic favors diffuse white light or daylight. This convention has its roots in MoMA's first purpose-built building, which opened in New York in 1939. MoMA's influential first Director, Alfred Barr, fought for translucent, heat-resistant, and light-diffusing "Thermolux" glass windows to be incorporated into the gallery's design (Ricciotti 1985, p. 68; Klonk 2009, p. 145). This ensured that the artworks were lit according to his curatorial vision of how modernist artworks should be encountered: in diffuse day light. This helped to create the atmospheric conditions (airy, neutral, light) that became synonymous with the "white cube" model of modern and contemporary art, its experience, and its meanings. This is one way in which art gallery windows contribute to the establishment of the internal gallery atmosphere.

In this section I have argued that windows offer a lens through which to explore how issues of aesthetics, context, and atmosphere are negotiated in and around an art gallery. This is because windows partition zones of meaning; frame vision; contribute to the symbolic meanings of a gallery's exterior architecture; and modulate its interior atmosphere. As such, I have suggested that thinking with windows is a way to approach art galleries as spaces that are not only made meaningful by the artworks within them, but also by the textures of the social life that surrounds them. Despite the heterogeneity of spaces and places of art and its meanings, my focus here has been on the white cube gallery aesthetic and art galleries located in commercial Western urban centers due to the location of the field site that I detail in this paper. I will now turn to introduce this field site, as well as the methods I used and data I generated in researching this paper. 


\section{Field site, data and methods}

Studies of meaning making in the art gallery deploy a plurality of methods that illuminate the various epistemologies they rely on. Discourse-focused analyses often use participant observation to witness, record, and transcribe, conversations in the gallery space (Bruder and Ucok 2011; Adipa 2019). Studies interested in physical action in the gallery have used wearable mapping devices to chart and categorize gallery visitors' use of the space (Kirchberg and Tröndle 2015). Bourdieu and Darbel, in their influential study of the art gallery, used a questionnaire to gather data on participants' educational background and occupation (Bourdieu and Darbel 1991). However, my research interest in the gallery as a site of meaning, context, and atmosphere was better suited to the textured and fine-grained cultural analysis afforded by "thick description," which I accomplished through ethnographic fieldnotes and image making (Geertz 1973, p. 3).

The data for this paper was gathered during 14 months of fieldwork, from February 2017 until April 2018. My field site was Bluecoat, a center for contemporary art located in the commercial city center of Liverpool in the northwest of the UK. The period of fieldwork was designed to coincide with the development, installation, and consumption of an exhibition, In the Peaceful Dome, which ran from Friday 13th October 2017 until Sunday 8th April 2018 and took a historical view of the arts center as part of the tercentenary celebration of Bluecoat's building (Bluecoat 2017).

The data for this paper are predominantly drawn from the two-week installation period in October 2017 and subsequent public presentation of In the Peaceful Dome. This afforded me unique access to the process of the "setting of ambiance" that was introduced above (Thibaud 2015, p. 39). During the life of the exhibition, I volunteered as a gallery invigilator in order to spend time observing the social life of the galleries; helpfully, the invigilator's seat is placed in Bluecoat's window allowing for extended periods of observation during which I could unobtrusively take extensive notes. During the install, I similarly occupied the space as a volunteer.

I developed a methodology, informed by visual sociology (Harper 2012; Heng 2016), in which participant observation was blended with the use of the film camera. Unlike other explorations of the gallery that also utilize cameras (Lehn et al. 2001), I established myself in the field, in part, as a filmmaker who was interested in using the camera to capture the atmosphere and sensory aspects of the gallery (rather than simply recording the action in the site). ${ }^{4}$ Although it is beyond the remit of this paper to explore my full methodological framework, it is sufficient to note that my research methods were designed to sensitize me to non-discursive elements of the exhibition during its install and public life, and produced data to reflect this. Images included in this paper are stills from this filmed data.

The many hours of footage I recorded, the fieldnotes taken over the course of the full 14 months, and primary and secondary documents relating to Bluecoat (e.g.,

4 The resulting film Critical Focus: Study of an Arts Centre can be viewed online (Harris, 2021)

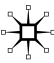


minutes of meetings, newspaper clippings) produced a large body of visual and ethnographic data. Filmed data was transcribed in a log. Qualitative data analysis software was used to systematically code the full data set. This process identified windows as a recurring motif and modifier of action in and around the gallery space, providing the framework for the analysis to which I now turn.

\section{Analysis: making meaning in and around Bluecoat's windows}

The Bluecoat Arts Center sits on College Lane, a pedestrian artery into the heart of the outdoor shopping complex "Liverpool One." Liverpool One has monopolized the central shopping zone of Liverpool since 2008, when this city in England's northwest was also celebrating its tenure as EU Capital of Culture (Figs. 1, 2). Both of these initiatives, Liverpool One and the EU Capital of Culture, were motivated by a desire to transform and rebrand Liverpool and the meanings attached to it from a city grappling with its post-industrial economic decline to a forward-looking, international, touristic city, using culture as an economic driver (Jones and Wilks-Heeg 2004). The magnitude of this rebranding exercise is reflected by the 250 -year lease on 42 acres of Liverpool's central retail zone that was granted to the developers of Liverpool One. Although the wear and tear of 13 years of footfall is present in Liverpool One's streets like College Lane, the vast, inhuman timescale of the development makes itself felt through its architecture. The luster of its buildings and the

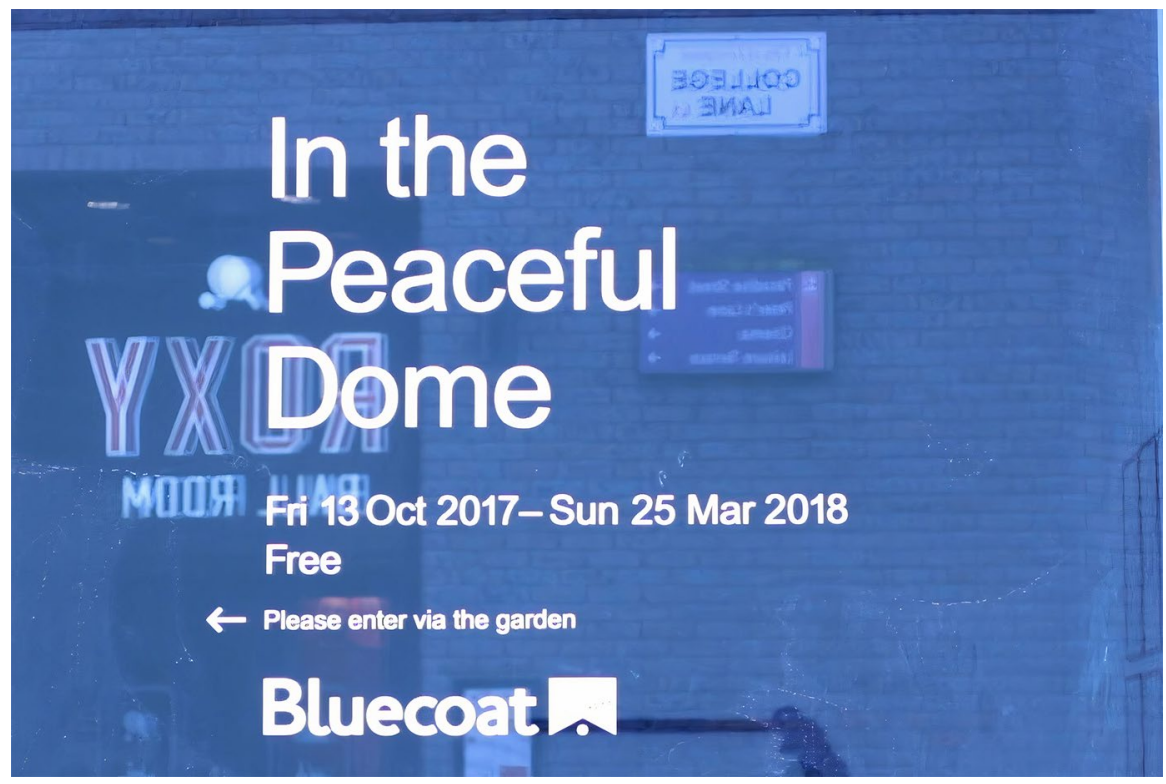

Fig. 1 Window decals advertise the exhibition "In the Peaceful Dome," while the street sign for "College Lane" is reflected in the window. Copyright: Laura Harris. 


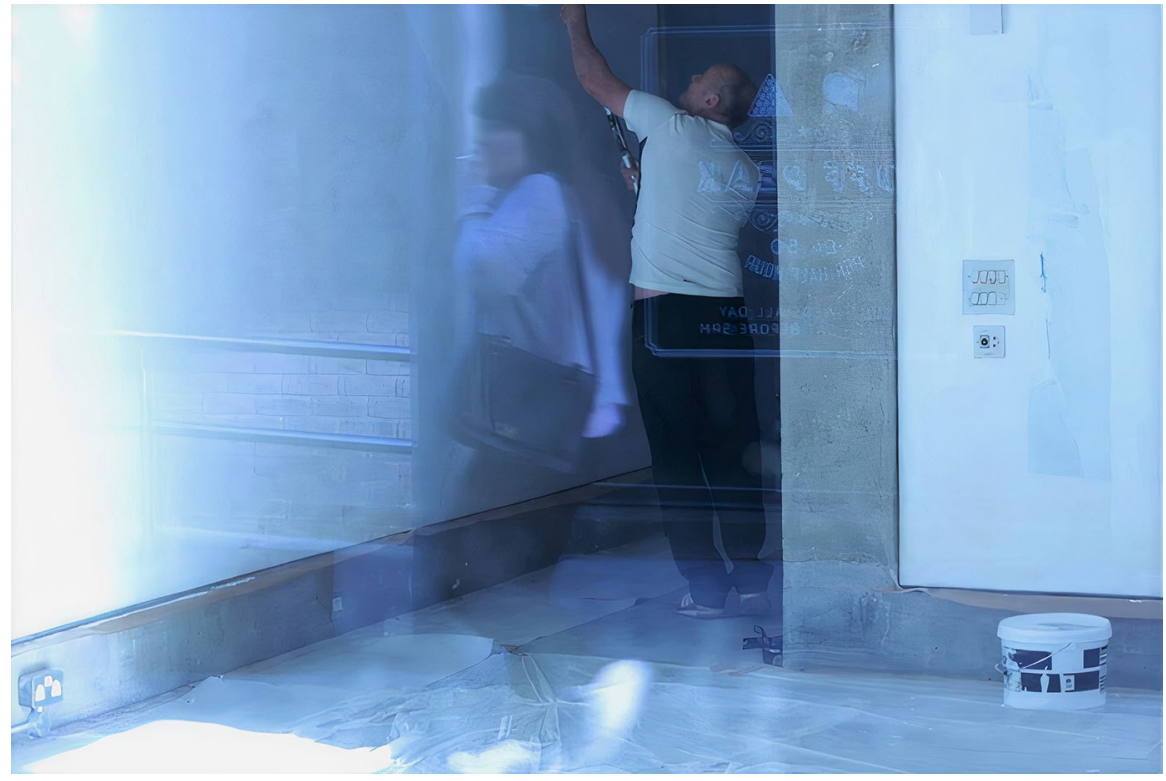

Fig. 2 A gallery technician paints the gallery walls white, while a passing pedestrian is seen reflected in the window. Copyright: Laura Harris.

permanence of their materials are designed to reify the allure of shopping, of owning, and of exchange for centuries to come.

In an attempt to lend Liverpool One the feel of architectural bricolage that gives urban spaces their character, 26 different architectural firms were recruited. Each was responsible for imbuing a commercial building or zone with a unique atmosphere. College Lane's atmosphere is relatively upmarket and polished. It is designed on a human scale, with one- or two-story buildings. On the Lane's north end, Liverpool One branded bins mark one edge of the shopping complex, and a pelican crossing releases pedestrians in short, regular, and noisy bursts from the supermarket over the road. The shops of College Lane are at the upper end of the high-street economy and are a mixture of international brands and local independent businesses. From artisan ceramics, to designer fashion behind security guards, College Lane is one of the more expensive, luxury zones of Liverpool One. The reddish bricks found across the city - a relic of Liverpool's industrial past found at the Albert Dock and the vast warehouses north of the city center-are here juxtaposed with smooth black slabs and large shop windows, an architectural attempt to texture this street with hints of the city's historical character, smoothed over into its commercial present.

Bluecoat's main building was built in 1717 as a school and is of a highly ornamental and grandiose Queen Anne architectural style. However, a 2008 redesign of the arts center (coinciding with both Liverpool's tenure as EU Capital of Culture and the opening of Liverpool One) saw one wing of the building transformed into a series of flexible gallery spaces culminating in a gallery that interfaces directly with College Lane. The redesign was completed by the architectural firm Hans van 
der Heijden, whose design left much of the exterior of the art center intact, while adopting a contemporary, minimalist aesthetic for the wing of galleries. Appropriateness to "context" was key to the design brief and Hans van der Heijden designed Bluecoat's College Lane exterior such that it fits in smoothly with its surroundings (Hans van der Heijden 2008; ArchDaily 2008). Its red brickwork echoes that found elsewhere on College Lane, but with a sharper, more contemporary aesthetic. One corner of the gallery's exterior is tiled with black marble, engraved in gold with the Roman numerals for 2008. Externally, therefore, Bluecoat fits into the narrative and codes of College Lane, and of Liverpool, as a place that is made meaningful by the co-presence of commerce and culture.

A key aspect of Hans van der Heijden's design is a series of three ground-floor windows that run the length of the gallery, affording floor-to-ceiling views of the gallery space from College Lane and vice versa. College Lane affords its pedestrians a sequence of windows arranged at eye level, each window frame displaying a desirable mise-en-scène of commodities. Of the various window glasses available to Bluecoat's architects - from mirrored glass, to obscured glass, to frosted glass- they opted for a smooth glass with an undisrupted surface, strong enough to stand several yards tall without internal support, and which affords undistorted vision to bisect its plane. These windows relate to the vogue for gallery façades made of transparent glass, correspond visually and materially with neighboring shop windows, and appear consistent with the codes of meaning and behavior that operate on the shopping street. Bluecoat's curatorial and programming team occasionally referred to this window as the "shop window," recognizing its potential to attract the attention of passers-by and convert them into visitors (Image One shows window decals used to direct this traffic). The "rhythm" of the windows was purposefully designed to "echo but... not imitate" windows elsewhere in Bluecoat's Queen Anne-style building, thereby positioning the gallery façade relative to the art center as a whole (ArchDaily 2008). The commanding presence of these glossy, glassy windows in the overarching design language of the gallery's façade serves to ingratiate Bluecoat with the logics that sit behind the redevelopment of Liverpool's city center, while also materializing the trend for "open" and accessible contemporary art gallery architecture.

However, the ingratiation of Bluecoat's external façade with the atmosphere of College Lane sometimes created conflicts at the site of the window. By focusing on practices of looking during my fieldwork, I observed how the mise-en-scène offered within the frame of Bluecoat's windows punctured the expectations of a typical shop window. For the exhibition under analysis, Bluecoat's curatorial team had arranged for a sculpture, Genesis, to be displayed in the central window of the gallery (Epstein 1929-1931). The sculpture was first exhibited at Bluecoat in 1931, and its inclusion in In the Peaceful Dome was justified by this historical connection. Genesis is a sculpture by American-British modern artist Jacob Epstein. It stands at 162 centimeters tall and is made of Servezza marble. It depicts a nude, heavily pregnant woman with "exaggerated thighs, hands and stomach" (Cronshaw 2010, p. 211). The facial features reproduce the "African mask" trope in $20^{\text {th }}$ century European Art. As Charmaine Nelson makes clear, this depiction of pregnancy combined with nudity sits within a canon of reductionist and racializing representations of Black womanhood 
in European Art (Nelson 2010, p. 27). Genesis concentrates intersecting racial and gendered prejudices in European Modern art in its main focal point: the deliberately and disproportionately enlarged belly. Genesis' formal distortions have historically been met with criticism, and considered "ill-judged" (Cork 1999, p. 51 in Cronshaw 2010 , p. 214) and, by the popular press of the 1930s, "ugly" (Cronshaw 2010, p. 218). ${ }^{5}$

Genesis' appearance is conspicuous. This informed the curatorial decision to place the sculpture in the central window facing College Lane, the most outwardly visible spot of the exhibition, thereby prioritizing the viewpoint of the street over the viewpoint of those entering the gallery. The relatively sparse arrangement of other artworks in the gallery space served to further visually emphasize Genesis. As a consequence, Genesis was often the subject of "double takes" from College Lane, with many passers-by pointing to it and bringing it to the attention of their companions in a manner of shock or surprise. In one example, a child stopped in front of the gallery windows, and "stuck out his belly" to draw his adult companions' attention to the sculpture's form. Conversely, inside Bluecoat's gallery Genesis was routinely approached with a degree of quiet reserve and reflection. Visitors stood at least a yard away from the sculpture, adopting a practice of looking cued by the gallery, which anticipates incongruities in visual perception. As such, the spatial relationships between the viewer of Genesis, the gallery space, and the street were implicated in how viewers oriented themselves towards the sculpture.

The difference in these practices of looking illuminate Smart's parallel concepts of "openness" and "transparency" with regards art gallery architecture (Smart 2020). The culture for openness and inclusivity that informs art gallery architecture, and specifically the prominent use of windows, imagines a bringing together of external and internal spaces, a collapsing of the distinction between zones of meaning, and an integration of different publics, in different positions, into the meaningful space of the art gallery. However, the example of Genesis highlights the obstacles to this "openness." The different orders of meaning cued by the spaces of the gallery and the street conflicted, in effect "enclosing" the artwork in the internal gallery space. In this example, the transparency of the windows was therefore insufficient to produce the openness of the gallery space.

Spatial aspects of gallery-situated meaning making were further evidenced by the windows. As well as affording inward vision, the transparent window also made visible and framed the animation of College Lane from the viewpoint of the gallery. However, an asymmetry in window-oriented visual practices was evident as the exhibition unfolded. Far more passers-by looked into the gallery than gallerygoers looked out. Gallerygoers instead oriented their sensory attention towards the objects presented as artworks. This involved negotiating the various perspectives within the gallery space, with the outward-facing position of Genesis requiring gallerygoers to insert themselves between the window and the sculpture. The apparent indifference of gallerygoers to the prominent visual presence of College Lane made clear that the animation of the street was not relevant to their meaningful experience of the

\footnotetext{
5 I have chosen not to reproduce this sculpture. Should a reader wish to view it, other online platforms have published it (see ArtUK 2021).
} 
gallery. In other words, for gallerygoers the gallery can present a totalizing context for meanings within it; in comparison, the shopping street is made sensible in reference to things elsewhere (i.e., in shops). This further emphasizes how routines of gallery-situated meaning making are illuminated by attention to contextual factors.

The visual presence of College Lane in the gallery space also acted as the atmospheric "other" to the gallery space. Bluecoat's gallery depends on volunteer invigilators who supervise the artworks on display and provide information to gallerygoers. On registering as a gallery invigilator, volunteers are presented with a manual that instructs them to "maintain a quiet and studious atmosphere in the galleries-much like a library," and that the "galleries should be quiet and contemplative spaces where audiences are able to engage with art works without distraction" (Bluecoat 2017, personal communication) The studious atmosphere produced, in part, by the labor of gallery invigilators is the sonic correlate of the visual white cube gallery aesthetic, aimed at creating a neutralizing, distractionless aural environment in which the artworks command full attention. At Bluecoat, the internal gallery atmosphere was the antithesis of the atmosphere of College Lane-of urbanity, busyness, and noisiness - and the generation of the gallery's atmosphere, or the "setting of ambience," depended on the exteriorization of the street (Thibaud 2015, p. 39). The windows helped towards this by framing the action of the street, lending it a degree of abstraction, while also serving to insulate the gallery from external sounds and climate.

At the same time, the windows provided (during laylight hours) a source of ambient and "neutral" light suited to the internal gallery aesthetic. To a degree, the gallery was consequently suffused with the quality of the external daylight. However, lighting strategies were employed to support and enhance this. The lighting of the gallery space was designed such that the interior space was held together as a visual whole. Shop windows often spotlight items in the window display and the display itself stands as a representation or idealized version of what is available in, or desirable about, the shop. Bluecoat's lighting design, by contrast, allowed it to subtly highlight artworks visually set within the cohesive whole of the gallery space, while angling the general artificial lighting away from the window. This prevented any glare on the glass in the service of vision passing through its plane, while also illuminating the whole of the gallery in such a way as to subtly enhance its distinction from the passing street. Such strategies with light pushed against the visual contamination of one space with the other, further visually differentiating the gallery from its neighboring territories of meaning.

So far, I have evidenced how Bluecoat is ingratiated in Liverpool's urban fabric, as well as how the gallery was differentiated from the meanings circulating in College Lane. However, as Smart makes clear, art gallery windows also create the potential for meaning to spill out from the gallery and for the gallery to become "open." On occasion, Bluecoat's gallery window's transparency gave way to this "openness." For example, near the end of the installation period, Genesis was carefully unwrapped by gallery technicians. The process of bringing the sculpture to Bluecoat had required a long administrative process, a high-profile fundraiser, and many different workforces and skill sets. As a result, the moment of unwrapping was treated with a degree of ceremony by those involved in the process. Bluecoat's staff 
and gallery technicians gathered in the gallery space around the sculpture, as the opaque protective wrapping was peeled away. Outside the window, a small crowd began to gather, seemingly attracted by the unusual events unfolding within the gallery. Like those within the gallery, this gathered crowd watched with anticipation as the sculpture emerged from its wrapping, with many members of the crowd staying for the duration of the unveiling. The window created the possibility for this assembly to gather in and around the gallery, and to participate in the meanings being produced in and by the moment of Genesis' unwrapping. This example demonstrates that meanings in and around the gallery fluctuate through time, and that the gallery and its neighboring spaces can be both held apart and held together through the divergence or sharing of meaningful practices of looking. While the meanings of College Lane and those of the Bluecoat's gallery tended to contrast, they were nonetheless held in a dynamic tension with one another, a tension that could break through the simple act of unwrapping a sculpture seen through a window.

In this analysis I have used Bluecoat's gallery windows as a lens to evidence the unsettled processes through which meaning is ordered in and around the gallery. This has included how the gallery relates to the meanings and atmospheres of its context. In so doing, I have modeled an approach to a meaning-centered sociology of the art gallery, which, strengthened by its attention to context and atmosphere, is alive to the real-time contestation of gallery-situated meanings such as those that occurred at the site of Bluecoat's street-facing windows.

\section{Conclusion}

The longstanding sociological interest in visual art, its meanings, and its places has often been conducted in the shadow of overly discursive and interaction-based understandings of art. The conversations, gestures, and interpretative strategies within galleries have all been studied as if they contain the meanings of artworks and, consequently, of galleries. More broadly, the longstanding sociological interest in visual art also has been conducted in the shadow of sociological theories and methods that overlap meaning with discourse and study it accordingly. I have pushed against this. In so doing I have drawn together sociologists (Bartmanski and Alexander 2012; de la Fuente 2019), art historians (Klonk 2009), and art theoreticians (Sontag 1966), who all variously make the case that meanings, and not least artful meanings, emerge from a concatenation of cultural, aesthetic, experiential, and spatial influences. I have condensed these various critiques into the headings "contexts" and "atmospheres." In place of interaction-based studies of the art gallery, which usher in a blunted and dulled version of meaningful art experiences, I have argued that sociological understandings of gallery-situated meaning making benefit from a more expansive view of the diverting aspects of galleries as they are lived and felt in time and place.

Taking this approach to an empirical study of an art gallery required me to devise a strategy through which to study how "contexts" and "atmospheres" shape the production of gallery-situated meanings in real time. The specifics of the art gallery under analysis, Bluecoat, based in Liverpool's shopping district, suggested the series 
of three windows that mediate between the art gallery and the city street as a fruitful and appropriate device. Locating my study at the gallery windows allowed me to observe and analyse how contextual and atmospheric conditions-from lighting, to sound, architecture, the history of Liverpool, and the grammar and conventions of shop windows - fed into the animation of Bluecoat's gallery as a distinctly meaningful space. Taken as an object of sociological study, these windows afford me a view of the codes, narratives, and conventions that played across and through their glassy surface.

Beyond the analysis of Bluecoat's gallery, the contributions of this paper are twofold. Firstly, I have modeled what a meaning-centered sociology of the art gallery that "looks beyond interpretation" might be. The alternative approach I have taken in is deeply textural (de la Fuente 2019), an approach that is beginning to emerge in empirical studies of social life, such as Amsterdam's café culture (Kuruoğlu and Woodward 2021). This approach lends itself particularly well to the study of art and its places, especially those works and places that tend to distort and exceed conventional modes of meaning making while appealing to aesthetic and sensual experience. A key aspect of this approach is its site specificity, which acts as a corrective to the often placeless, or unrooted, studies of inter-gallery group interaction. However, art is experienced in settings far beyond the gallery walls-including land art, street art, and digital art-each of which will provide new terrains for textural sociological attention.

The second contribution is the use of windows as a device through which to conduct a cultural sociology of the built environment, and of art galleries in particular. Architecture has already emerged as a key interest within the "iconic turn," opening the door for analyses of distinct architectural features. Windows intervene in social life, provide aesthetic surfaces, uphold meaningful distinctions, and feed into architectural design languages. They contribute to the atmospheres of buildings, streets, and cities. As a sociological device, windows have already been used to great effect in studies of social divisions in and around domestic spaces (Hirsch and Smith 2017; Mosteanu 2021). A distinctly cultural approach to windows can reveal the contestation of meaning in many shared social spaces, like the art gallery of this paper or a religious building, where divergent zones of meaning are brought together through the windowpane.

Acknowledgments I have benefitted greatly in developing this paper from Eduardo de la Fuente's comments on an early draft, as well as the generous and generative feedback of the reviewers and editor.

\section{References}

Acord, S. 2016. Learning how to think, and feel, about contemporary art: An object relational aesthetic for sociology. In Handbook of the Sociology of Art and Culture, ed. L. Hanquinet and M. Savage, 219-231. Abingdon: Routledge.

Adipa, P. 2019. Talking events: How social interaction and discourse shape cultural participation, aesthetic evaluation, and meaning-making. Poetics 77: 1-11.

Alexander, J. 2003. The Meanings of Social Life: A Cultural Sociology. Oxford: Oxford University Press. Alexander, J. 2010. Iconic consciousness: The material feeling of meaning. Thesis Eleven 103 (1): 10-25. 
Alexander, J. 2012. Iconic power and performance: The role of the critic. In Iconic Power: Materiality and Meaning in Social Life, ed. J. Alexander, D. Bartmanski, and B. Giesen, 25-38. New York: Palgrave Macmillan.

ArchDaily. 2008 The Bluecoat/Hans van der Heijden Architect. Retrieved June 5, 2021 from https://www. archdaily.com/536235/the-bluecoat-hans-van-der-heijden-architect.

ArtUK. 2021. Genesis. Retrieved August 17, 2021 from https://artuk.org/discover/artworks/genes is-258823\#.

Bartmanski, D., and J. Alexander. 2012. Introduction: Materiality and meaning in social life: Toward an iconic turn in cultural sociology. In Iconic Power: Materiality and Meaning in Social Life, ed. J. Alexander, D. Bartmanski, and B. Giesen, 1-14. New York: Palgrave Macmillan.

Bartmanski, D., and I. Woodward. 2019. Labels: Making Independent Music. London: Bloomsbury.

Becker, H., and M. McCall. 1990. Symbolic Interaction and Cultural Studies. Chicago: University of Chicago Press.

Bishop, C. 2012. Artificial Hells: Participatory Art and the Politics of Spectatorship. London: Verso.

Bluecoat. 2017. In the Peaceful Dome. Retrieved May 23, 2021 from http://www.thebluecoat.org.uk/ events/view/exhibitions/3591.

Borch, C. 2014. Architectural Atmospheres: On the Experience and Politics of Architecture. Basel: Birkhäuser.

Bourdieu, P., and A. Darbel. 1991. The Love of Art. Cambridge: Polity Press.

Bourriaud, N. 1998. Relational Aesthetics. Dijon: Les Presses du Réel.

Bowlby, R. 2001. The Passer-by and the Shop Window. In Carried Away: The Invention of Modern Shopping, ed. R. Bowlby, 49-78. New York: Columbia University Press.

Bruder, K., and O. Ucok. 2011. Interactive art interpretation: How viewers make sense of paintings in conversation. Symbolic Interaction 23 (4): 337-358.

Christidou, D. 2018. Art on the move: The role of joint attention in visitors' encounters with artworks. Learning, Culture and Social Interaction 19: 1-10.

Christidou, D., and P. Pierroux. 2019. Art, touch and meaning making: An analysis of multisensory interpretation in the museum. Museum Management and Curatorship 34 (1): 96-115.

Classen, C. 2007. Museum manners: The sensory life of the early museum. Journal of Social History 40 (4): 895-914.

Cotter, K., A. Fekete, and P. Silvia. 2021. Why do people visit art museums? Examining visitor motivations and visit outcomes. Empirical Studies of the Arts 1: 1-21.

Crimp, D., and L. Lawler. 1993. On the Museum's Ruins. Cambridge: MIT University Press.

Cronshaw, J. 2010. Carving a Legacy: The Identity of Jacob Epstein (1880-1959). PhD Thesis, University of Leeds, Leeds, UK.

Danto, A. 1998. After the End of Art: Contemporary Art and the Pale of History. Princeton: Princeton University Press.

de la Fuente, E. 2019. After the cultural turn: For a textural sociology. The Sociological Review 67 (3): 552-567.

de la Fuente, E. 2020a. Both-And: On the Need for a Textural Sociology of Art. Caderno CRH 32 (87): 475-488.

de la Fuente, E. 2020b. Living in a textured world: Sociology and contextual intelligence. Retrieved May 13, 2021 from https://www.thesociologicalreview.com/living-in-a-textured-world-sociology-andcontextual-intelligence/.

de la Fuente, E., and M. Walsh. 2020. Framing atmospheres: Goffman, space, and music in everyday life. Symbolic Interaction 44 (1): 211-234.

DeNora, T. 2000. Music in Everyday Life. Cambridge: Cambridge University Press.

Denzin, N. 2003[1992]. Symbolic Interactionism and Cultural Studies: The Politics of Interpretation. Oxford: Blackwell.

Dickie, G. 1974. Art and the Aesthetic: An Institutional Analysis. Ithaca: Cornell University Press.

Edensor, T. 2017. From Light to Dark: Daylight, Illumination, and Gloom. Minneapolis: University of Minnesota Press.

Edensor, T., and S. Sumartojo. 2015. Designing atmospheres: Introduction to special issue. Visual Communication 14 (3): 251-265.

Epstein, J. 1929-1931. Genesis. The Whitworth, University of Manchester, Manchester.

Eyerman, R., and M. Ring. 1998. Towards a new sociology of art worlds: Bringing meaning back in. Acta Sociologica 41 (3): 277-283.

Falk, J., and L. Dierking. 2011[1992]. The Museum Experience. Abingdon: Routledge. 
Fernándes López, O., A. Klett, and Z. López Mediero. 2021. Curatorial practice as (place) making: Social imagination, cultural laboratories, and public space in Madrid (2008-2015). In Socially Engaged Art History and Beyond: Alternative Approaches to the Theory and Practice of Art History, ed. C. Persinger and A. Rejaie, 159-180. Cham: Palgrave Macmillan.

Garrison, J. 2015. Glass. London: Bloomsbury.

Geertz, C. 1973. The Interpretation of Cultures. New York: Basic Books.

Griswold, W., G. Mangione, and T. McDonnell. 2013. Objects, words, and bodies in space: Bringing materiality into cultural analysis. Qualitative Sociology 36: 343-364.

Gumbrecht, H., and K. van den Berg. 2010. Politik des Zeigens. Leiden: Brill.

Halle, D. 1993. Inside Culture: Art and Class in the American Home. Chicago: University of Chicago Press.

Harper, D. 2012. Visual Sociology. Abingdon: Routledge.

Harris, L. 2021. Image-Maker in Residence: Laura Harris. Retrieved October 7, 2021 from https:// thesociologicalreview.org/magazine/march-2021/art-and-representation/image-maker-in-resid ence-laura-harris/.

Heath, C., and D. vom Lehn. 2004. Configuring Reception: (Dis-)regarding the "spectator" in museums and galleries. Theory, Culture, Society 21 (6): 43-65.

Heng, T. 2016. Visual Methods in the Field: Photography for the Social Sciences. Abingdon: Routledge.

Hirsh, S., and A. Smith. 2017. A view through windows: Social relations, material objects and locality. The Sociological Review 66 (1): 224-240.

Inglis, D. 2010. Politics and reflexivity in the sociology of art. Sociologie D'art 15 (1): 113-135.

Ingold, T. 2012. The atmosphere. Chiasmi International 14: 75-87.

Jones, P. 2020. Architecture, time, and cultural politics. Cultural Sociology 14 (1): 61-79.

Jones, P., and S. Wilks-Heeg. 2004. Capitalising culture: Liverpool 2008. Local Economy: the Journal of the Local Economy Policy Unit 19 (4): 341-360.

Kester, G. 2013. Conversation Pieces: Community and Communication in Modern Art. Berkeley: University of California Press.

Kirchberg, V., and M. Tröndle. 2012. Experiencing exhibitions: A review of studies on visitor experiences in museums. Curator - the Museum Journal 55 (4): 435-452.

Kirchberg, V., and M. Tröndle. 2015. The museum experience: Mapping the experience of fine art. Curator - the Museum Journal 58 (2): 1-25.

Klonk, C. 2009. Spaces of Experience. New Haven: Yale University Press.

Kobyshcha, V. 2018. How does an aesthetic object happen: Emergence, disappearance, disappearance, multiplicity. Cultural Sociology 12 (4): 1-21.

Kuruoğlu, A.P., and I. Woodward. 2021. Textures of diversity: Socio-material arrangements, atmosphere, and social inclusion in a multi-ethnic neighbourhood. Journal of Sociology 57 (1): 111-127.

Lehn, D., C. Heath, and J. Hindmarsh. 2001. Exhibiting interaction: Conduct and collaboration in museums and galleries. Symbolic Interaction 24 (2): 189-216.

Lindsay, G. 2020. Contemporary Museum Architecture and Design: Theory and Practice of Place. Abingdon: Routledge.

Lopez-Sintas, J., E. Garcia-alvarez, and E. Perez-Rubiales. 2012. The unforgettable aesthetic experience: The relationship between the originality of artworks and local culture. Poetics 40 (4): 337-358.

Luckman, S. 2020. People, places, and processes: crafting authenticity through situating the local in the global. In Handbook on the Geographies of Creativity, 162-178. Massachusetts: Edward Elgar.

Macgregor, E. 2020. Iconic or engaging? Beyond the spectacle. In Contemporary Museum Architecture and Design: Theory and Practice of Place, ed. G. Lindsay, 9-22. Abingdon: Routledge.

MacLeod, S. 2013. Museum Architecture: A New Biography. Abingdon: Routledge.

McQuire, S. 2013. From glass architecture to big brother: Scenes from a cultural history of transparency. Cultural Studies Review 9 (1): 103-123.

Mosteanu, O. 2021. City flows during pandemics: zooming in on windows. In The COVID-19 Crisis: Social Perspectives, ed. D. Lupton and K. Willis, 53-66. Abingdon: Routledge.

Musuems + Heritage Advisor. 2019. National Gallery and King's College R\&D project explores 'gallery of the future.' . Retrieved June 26, 2021 from https://advisor.museumsandheritage.com/news/natio nal-gallery-kings-college-rd-project-explores-gallery-future/, 26 September.

Nelson, C. 2010. Representing the Black Female Subject in Western Art. Abingdon: Routledge.

O'Doherty, B. 2000[1976]. Inside the White Cube: The Ideology of the Gallery Space. Expanded. Berkeley: University of California Press. 
Patterson, M. 2019. Architecture as performance art: Evaluating "iconic power" in the development of two museums. American Journal of Cultural Sociology 8 (1): 158-190.

Pierroux, P. 2010. Guiding meaning on guided tours. Narratives of art and learning in museums. In Inside Multimodal Composition, ed. A. Morrison, 417-450. Cresskill: Hampton Press.

Reich, M. 2020. Making an urban living room: Musuem of contemporary art Cleveland, Ohio, US. In Contemporary Museum Architecture and Design: Theory and Practice of Place, ed. G. Lindsay, 86-104. Abingdon: Routledge.

Ricciotti, D. 1985. The 1939 building of the museum of modern art: The Goodwin-Stone collaboration. The American Art Journal 17 (3): 50-76.

Scott, A. 2000. The Cultural Economy of Cities: Essays on the Geography of Image-Producing Industries. London: Sage.

Scott, S., T. Hinton-Smith, V. Harma, and K. Broome. 2013. Goffman in the gallery: interactive art and visitor shyness. Symbolic Interaction 36 (4): 417-438.

Seamon, D. 2020. International Lexicon of Aesthetics. Retrieved June 1, 2021 from https://lexicon.mimes isjournals.com/international_lexicon_of_aesthetics_item_detail.php?item_id=90.

Smart, W. 2020. The open and integrated museum. In Contemporary Museum Architecture and Design: Theory and Practice of Place, ed. G. Lindsay, 137-154. Abingdon: Routledge.

Smith, R. 2011. Romantics shining clear light on daily existence. Retrieved June 2, 2021 from https:// www.nytimes.com/2011/04/08/arts/design/rooms-with-a-view-at-the-metropolitan-museum-of-artreview.html, 7 April.

Sontag, S. 1966. Against Interpretation and Other Essays. New York: Farrar, Straus and Giroux.

Steffensen-Bruce, I. 1998. Marble Palaces, Temples of Art: Art Museums, Architecture, and American Culture, 1890-1930. London: Bucknell University Press.

Steier, R., P. Pierroux, and I. Krange. 2015. Embodied interpretation: Gesture, social interaction, and meaning making in a national art museum. Learning, Culture, and Social Interaction 7: 28-42.

Thibaud, J. 2015. The backstage of urban ambiances: When atmospheres pervade everyday experience. Emotion, Space, Society 15: 39-46.

Thompson, K. 2020. Museum as Place-Maker. In Contemporary Museum Architecture and Design: Theory and Practice of Place, ed. G. Lindsay, 105-118. Abingdon: Routledge.

Thompson, N. 2012. Living as Form: Socially Engaged Art from 1991-2011. Cambridge: MIT Press.

van der Heijden, H. 2008. The Bluecoat. Retrieved May 27, 2021 from https://hvdha.com/en/the-bluec oat-liverpool/.

Van Leyn, A., and E. de la Fuente. 2019. Regional Cultures, Economies, and Creativity: Innovating Through Place in Australia and Beyond. Abingdon: Routledge.

Velthuis, O. 2005. Talking Prices: Symbolic Meanings of Prices on the Market for Contemporary Art. Princeton: Princeton University Press.

Zerubavel, E. 1991. The Fine Line: Making Distinctions in Everyday Life. Chicago: University of Chicago Press.

Publisher's Note Springer Nature remains neutral with regard to jurisdictional claims in published maps and institutional affiliations.

Laura Harris is an ESRC Postdoctoral Fellow in Sociology at the University of Edinburgh. She completed her $\mathrm{PhD}$ in collaboration with Bluecoat, a contemporary arts centre in Liverpool, in 2020. 